\title{
LOS PUEBLOS INDÍGENAS DE LA AMAZONÍA PERUANA Y EL USO POLÍTICO DE LOS MEDIOS DE COMUNICACIÓN
}

\author{
Oscar Espinosa*
}

El presente artículo se basa en los resultados preliminares de una investigación en curso sobre el uso político de los medios de comunicación por parte de los Pueblos Indígenas de la Amazonía peruana. En el primer caso veremos cómo el pueblo Shipibo hizo uso de la radio en el proceso de construcción de su identidad étnica y en la creación de sus organizaciones políticas representativas. En la segunda parte veremos cómo los pueblos Asháninka y Aguaruna entran en relación con el Estado y los medios de comunicación, para redefinir, a través de las imágenes presentadas en la televisión, lo que se entiende por identidad nacional en el contexto de diferentes conflictos armados. Finalmente, voy a presentar el uso de Internet por el pueblo Asháninka. Estos casos corresponden a diferentes momentos históricos, y tienen como actores principales a pueblos que viven en distintos lugares de la Amazonía peruana '. De esta manera podemos hacernos una idea general de lo que ocurre, pudiendo al mismo tiempo ver las diferencias y semejanzas, las continuidades y rupturas. Pero antes de pasar a la discusión de cada uno de estos casos, quiero hacer unas observaciones previas.

Es necesario situar la acción política de los Pueblos Indígenas de la Amazonía peruana en un contexto histórico más amplio. Durante siglos estos pueblos se han visto obligados a resistir y luchar contra la dominación y hegemonía de otras gentes y culturas. Esta lucha adquirió la forma de «movimiento indígena» sólo a partir de la década de los sesenta. A partir de entonces, muchos Pueblos Indígenas de la Amazonía han creado nuevas organizaciones políticas a nivel regional, nacional e internacional. Sin duda, el factor étnico constituye uno de los elementos claves en este proceso de articulación de intereses, pero no es el único. La mayoría de estas organizaciones fueron creadas con la finalidad de representar los intereses de estos pueblos frente al Estado. Las principales demandas de estos pueblos son el respeto a las tierras o territorios ancestrales y a la propia cultura, así como servicios básicos de salud y educación (bilingüe). En este sentido puede resultar sugerente parafrasear a Eliseo Verón (1986) y señalar que estas organizaciones indígenas se constituyen como actores sociales y políticos a partir de la enunciación de un discurso específico, en este caso, dirigido fundamentalmente al
Estado. Es decir, no se trata de organizaciones pensadas principalmente para el gobierno interno de los propios pueblos, como sí ocurre con otro tipo de organizaciones políticas. Desde el momento de su creación, estas organizaciones asumieron el mismo lenguaje del Estado, un len guaje básicamente jurídico. Al mismo tiempo comenzaron a revisar y redefinir sus instituciones políticas tradicionales siguiendo las pautas y modelos proporcionados por el Estado nacional. Sin embargo no podemos olvidar que la relación establecida entre estos pueblos y el Estado perua no es absolutamente asimétrica. En el Perú, los pueblos indígenas ocupan -siempre han ocupado- un lugar marginal. Por lo tanto, esta relación está marcada sobre todo por tensiones y conflictos, aunque en algunos momentos también podemos encontrar colaboración y alianzas estratégicas. Así, a través de estas organizaciones, los pueblos indígenas de la Amazonía han podido hacerse más visibles y actuar políticamente en distintos espacios públicos.

\section{IDENTIDAD ÉTNICA Y ORGANIZACIÓN POLÍTICA: EL USO DE LA RADIO POR EL PUEBLO SHIPIBO}

El pueblo Shipibo vive a lo largo del río Ucayali y sus afluyentes, territorio que comparte con otros dos pueblos de lengua Pano, los Shetebo y los Conibo. Antiguamente, los Conibo y los Shetebo tenían más población y eran más poderosos que los Shipibo. Sin embargo, después de la llegada de los conquistadores y misioneros españoles, los grandes asentamientos Shetebo y Conibo desparecieron, y su población se redujo debido a las epidemias, además de la explotación y a los constantes asaltos y abusos sufridos. Los Shipibo, que vivían en sectores más alejados del río, se beneficiaron indirectamente, convirtiéndose en un pueblo

Investigador del Centro Amazónico de Antropología y Apli cación Práctica (CAAAP) y candidato a Doctor en Antropología e historia por la New School for Social Research de Nueva York.

1. Los pueblos a los que aquí me refiero, los pueblos Asháninka, Aguaruna, y Shipibo, son los más numerosos de la Amazonía peruana. Según el último Censo Nacional del Perú, de 1993, hay unos 60 mil Asháninka, 50 mil Aguaruna, y unos 20 mil Shipibo. 
más fuerte y numeroso, y con el tiempo llegaron a ocupar las mejores tierras en las riberas de los ríos, empujando a los Conibo hacia el sur y a los Shetebo hacia el norte. Por ello, hoy en día el valle del Ucayali puede dividirse en tres partes, cada una correspondiendo a un pueblo: los Conibo en el Alto Ucayali, los Shipibo en el Medio Ucayali, y los Shetebo en el Bajo Ucayali (el río Ucayali corre de sur a norte). Con el paso del tiempo, estos tres pueblos se han integrado cada vez más entre sí debido no sólo a alianzas matrimoniales, sino también por la reducción demográfica de muchas comunidades Shetebo y Conibo. Así, hoy en día se consideran parte de una única y gran «Nación Shipibo» (Vallejo, 1994: 17). En la actualidad existen más de un centenar de comunidades Shipibo ubicadas a lo largo de un extenso territorio, de tal manera que puede tomar varios días para ir, en bote por el río, de una comunidad a otra. En este sentido, la introducción y uso de la radio fue muy importante para conectarse unos con otros.

Al final de la década de los sesenta, el pueblo Shipibo comenzó a crear su propia organización étnica y política. Por supuesto, el Shipibo no constituía un caso único, sino que por el contrario, formaba parte de un proceso en el que muchos otros pueblos de la Amazonía (peruana y no peruana) también creaban organizaciones similares. Era una época en que también se producían importantes cambios sociales y políticos en el Perú, en América Latina, y en muchas otras partes del mundo.

De manera más concreta podemos ubicar los inicios de la organización Shipibo en los Congresos o Asambleas Generales que tuvieron lugar en 1971 y 1972. En mayo de 1971, aproximadamente unos ciento cincuenta delegados provenientes de diecinueve asentamientos diferentes se reunieron en la comunidad de Santa Rosa de Dinamarca. Esta reunión constituía el más grande «Anin Tsinkiti» (o «Asamblea General», en idioma Shipibo) de la historia de este pueblo. Para muchos delegados ésta era la primera oportunidad que tenía de conocer a otra gente Shipibo que provenía de lugares lejanos y de poder discutir juntos algunos de los asuntos y problemas que más les preocupaban entonces. Esta reunión tuvo tanto éxito, que organizaron tres más en el siguiente año y medio, cada vez incluyendo a más delegados de más comunidades. $\mathrm{Al}$ segundo encuentro, en Diciembre de 1971, asistieron aproximadamente mil delegados que venían de unos cincuenta asentamientos diferentes. El cuarto Congreso tuvo lugar en Octubre de 1974. En esta ocasión, el Presidente del Perú, el general Juan Velasco Alvarado, también asistió, lo cual constituía un caso excepcional, y demostraba el interés del gobierno por este tipo de organizaciones ${ }^{2}$. A esta reunión asistieron más de dos mil delegados provenientes de setenta y cinco comunidades (Chirif, 1974; Morin, 1992). Aunque estas Asambleas tuvieron mucho éxito, el pueblo Shipibo todavía tuvo que esperar otros diez años más antes de poder tener una federación que los representara oficialmente como pueblo. En esos diez años, intentaron diversas formas de organizacion, como las «Ligas Agrarias» y los «Frentes de Defensa» antes de crear la FECONAU (Federación de Comunidades Nativas del Ucayali).
En los primeros años de la organización, la radio cumplió un rol fundamental. A través de la radio, muchos Shipibo conocieron por primera vez lo que ocurría en otras comunidades, al mismo tiempo que se enteraban de lo que ocurría en otras partes de la región, del país y del mundo. Descubrieron que otros Shipibo también enfrentaban problemas similares y comenzaron a reconocer el mundo en común que compartían. La experiencia de la radio afianzó pues su sentido de comunidad y de identidad étnica. Al mismo tiempo, los líderes de la organización empezaron a usar la radio para comunicarse con su gente. Las distintas comunidades descubrieron así quiénes eran sus líderes y por qué causas luchaban. Así, cuando los líderes visitaban sus bases, la gente ya los conocía. Algunas personas recuerdan esta experiencia como marcada por un «toque mágico», por una fuerza simbólica especial.

La radio también definió muchas vidas en niveles más personales. Un líder Shipibo me contó que, siendo adolescente, escuchó en las noticias que un joven Shipibo había sido admitido a la universidad. Esto cambió su vida. El ya había acordado con sus padres que sólo estudiaría hasta terminar los primeros años de la secundaria. Pero cuando descubrió que alguien como él, otro joven Shipibo, estaba en la universidad, convenció a sus padres para que también lo dejaran ir a la universidad. En la actualidad no sólo tiene un título profesional y es un reconocido líder de su pueblo, sino además, desde hace varios años viene cumpliendo un rol importante en la producción de programas radiales Shipibo, e incluso ha logrado involucrar a otros jóvenes estudiantes Shipibo en esta tarea.

$\mathrm{Al}$ final de la década de los setenta, un grupo de líderes comenzaron a transmitir un pequeño programa radial en lengua Shipibo. Se trataba de un programa diario de sólo tres minutos de duración llamado «Manguaré Shipibo». El «manguaré» es un medio de comunicación tradicional entre los pueblos amazónicos que consiste en dos grandes troncos huecos que se golpean como tambores. A través del manguaré se enviaban mensajes de un asentamiento a otro. En 1980, fue creada la organización política oficial Shipibo (FECONAU). En este mismo año, la FECONAU asumió la producción del programa «Manguaré Shipibo» y lo convirtió en el programa oficial del pueblo Shipibo. Con este cambio, el programa fue ampliado, primero a cinco minutos, $\mathrm{y}$ luego a quince. Para entonces se le cambió el nombre y comenzó a llamarse «La Voz Nativa de Ucayali». Mucha gente todavía recuerda el primer día de transmisión de este nuevo programa, el 15 de Julio de 1980. Este programa se transmitía por «Radio Pucallpa», una de las principales radios privadas de la ciudad de Pucallpa. Por lo tanto, la

2. El gobierno de Velasco, debido a sus características peculiares, estuvo marcado por una serie de contradicciones. En cierto sentido, como cualquier dictadura militar buscaba controlar cualquier descontento social. Al mismo tiempo ha sido el gobierno más progresivo en la historia del Perú, aquel que ha hecho las más radicales reformas económicas y sociales, favoreciendo a las clases populares. Destruyó el poder político y económico de la oligarquía, y favoreció a las sectores capitalistas urbanos más modernos, mientras que también daba poder a los obreros, campesinos e indígenas. En algunos momentos mostraba características fascistas, y al mismo tiempo democratizaba la sociedad peruana. Para un interesan te y detallado análisis de este período, cf. Pease García, 1977. 
FECONAU tenía que pagar a los dueños de la radio por el tiempo asignado para el programa.

Con el tiempo, aparecieron otros programas radiales en Shipibo. Uno de ellos, que ha sido muy influyente, especialmente entre la gente joven se llamaba «Shinanya Joni», que significa «la gente que piensa» en idioma Shipibo. («Joni» significa «la gente», y es la manera en que los Shipibo se refieren a sí mismos en su propio idioma). Este programa fue transmitido durante nueve años, entre 1985 y 1993 . A partir de 1991, «Shinanya Joni» pasó a formar parte de la Asociación Cultural del mismo nombre, que realizaba otras actividades culturales además de la producción del programa radial. Este programa también contaba con una sección especial para el pueblo Piro (también conocido como Yine), también en su propio idioma. Tanto el programa como la Asociación Cultural Shinanya Joni, funcionaban con ayuda económica brindada por diferentes Organismos No Gubernamentales (ONGs) nacionales y extranjeros.

En 1991, apareció otro programa radial llamado «La Voz de la Selva» ${ }^{3}$ que tenía una hora de duración y se transmitía todos los domingos a las 2 de la tarde. Este programa fue creado por un líder Shipibo que había formado parte del grupo fundador de Shinanya Joni. La producción del programa correspondía a la «Fundación Cultural ShipiboConibo», dirigida por esta misma persona, y que también contaba con apoyo financiero de parte de diferentes ONGs. Este programa duró tres años, de 1991 a 1993. Posteriormente este mismo líder ha tomado parte en la producción de otros programas radiales, y sigue activo, tanto en la radio como en la política.

El uso del satélite por las radios privadas de Lima significó un fuerte golpe para los programas Shipibo. A partir de 1993, las grandes compañías de radiodifusión de Lima comenzaron a transmitir sus programas a nivel nacional. Esto obligó a las radios locales y regionales a volverse más competitivas si querían mantener sus audiencias. El costo de tiempo en el aire se incrementó, y los programas Shipibo «Shinanya Joni» y «La Voz de la Selva» tuvieron que cancelar su transmisión por razones puramente económicas.

Después de varios años, en 1997, fue relanzado el programa «La Voz de la Selva». Por supuesto, también se transmitía por una estación privada de radio de la ciudad de Pucallpa (Super AM/FM radio). Sin embargo, había perdido el horario estelar de los domingos por la tarde, y tenía que resignarse al horario madrugador de las 5 a las 5:30 de la mañana que resulta más barato. Además, este programa, a diferencia de los mencionados antes, no recibe ningún apoyo financiero y tiene que buscar auspiciadores y propaganda comercial para poder sostenerse. Para ser más competitivo, la gente a cargo del programa también ha creado su propia agencia de noticias, la Agencia de Prensa Indígena, para poder tener acceso a distintos eventos e información. También se han asociado a una red nacional de radios alternativas (la Coordinadora Nacional de Radio-CNR).

En la actualidad existen tres programas Shipibos que se transmiten en la región: «La Voz de la Selva», «Nonjoi» $\mathrm{y}$ «Nonrai». «Nonjoi» es producido conjuntamente por tres organizaciones Shipibo: Ametra (la Asociación de Medicina Tradicional), COCEBESH (el Comité Shipibo para Becas y Estudios) y «Huinanay» que es un grupo de estudiantes secundarios y universitarios Shipibo. Además, el conductor de «Nonjoi» es otro antiguo miembro de «Shinanya Joni». El otro programa, «Nonrai» is producido por una iglesia evangélica.

Estos programas son muy importantes para la mayoría de la gente Shipibo. No solamente porque a través de ellos reciben noticias e información de otros lugares en su propio idioma. A través de ellos, pueden saber de las vidas de otra gente Shipibo. Ahí donde no hay líneas telefónicas, la radio conecta a las personas que viven en lugares lejanos. Por la radio pueden enviar mensajes a los familiares o amigos, enterarse de la muerte de un pariente, y enviar saludos al que se encuentra de viaje. A través de estos programas se pueden comunicar en su propio idioma, y recordar cada día su pertenencia a un mismo pueblo. Pueden escuchar su música, su historia, sus tradiciones, cuentos y mitos. Se pueden reír de sus propios chistes y entretenerse resolviendo sus propios acertijos. Finalmente, pueden expresar sus problemas y necesidades cotidianas. Pueden denunciar la invasión de sus tierras o la destrucción de sus recursos naturales. Se pueden convocar reuniones y asambleas, y concertar acciones en común. En este sentido, la radio ha cumplido un importante rol para afianzar su identidad étnica y también para su acción política.

\section{LA IDENTIDAD NACIONAL EN TIEMPOS DE GUERRA: LOS ASHÁNINKA Y AGUARUNA EN LA TELEVISIÓN PERUANA}

En tiempos de guerra, las poblaciones indígenas se vuelven más visibles para sus conciudadanos. Esto ha sido una constante a través de la historia en distintos lugares del mundo. Por ejemplo, Donald Browne recuerda cómo durante la Segunda Guerra Mundial «las minorías indígenas sirvieron como miembros de las fuerzas armadas y como obreros en las industrias de defensa, haciéndose más visibles al interior de la vida nacional. Los indígenas eran descritos y entrevistados, no sólo en los artículos de diarios y revistas, sino también a través de la radio» (1996: 17).

En los últimos años, los Pueblos Indígenas de la Amazonía peruana se han visto involucrados en dos «guerras» diferentes. Una de ellas fue, lo que podríamos llamar de manera muy general una «guerra interna». Esta involucró a las Fuerzas Armadas nacionales y a dos partidos políticos armados (Sendero Luminoso y el Movimiento Revolucionario Túpac Amaru-MRTA). La otra correspondería a los enfrentamientos armados entre los ejércitos de Perú y Ecuador en zonas fronterizas y disputadas por ambos países ${ }^{4}$. La primera de estas guerras involucró al pueblo Asháninka, mientras que la segunda, al pueblo Aguaruna.

3. No confundir con la estación de radio de la ciudad de Iquitos que lleva el mismo nombre.

4. En 1998, después de décadas de tensión, enfrentamientos armados y negociaciones diplomáticas, se llegó a un acuerdo de paz entre los gobiernos del Perú y del Ecuador. 


\section{Los Asháninka: Guerreros Tradicionales, Héroes Modernos}

El pueblo Asháninka ha vivido durante siglos en la vertiente oriental de los Andes, en la región central de la Amazonía peruana. Su territorio es fácilmente accesible desde Lima y otras grandes ciudades. En la actualidad se puede llegar en unas seis horas en automóvil desde Lima hasta el valle del Chanchamayo, que corre en medio del territorio Asháninka. Sin embargo, durante siglos los Asháninka se han defendido frente a la invasión de foráneos. La única rebelión que no pudo ser controlada por las autoridades coloniales ocurrió precisamente en esta zona. La mayoría de los que tomaron parte en esta rebelión fueron Asháninka, aunque ésta fue liderada por Juan Santos Atahualpa, un indígena del Cuzco, perteneciente a la nobleza Inka, educado y muy carismático. Hoy en día el recuerdo de Juan Santos y su rebelión sigue inspirando a muchos Asháninka en sus luchas.

Debido a su ubicación geográfica, la historia de los Asháninka ha estado marcada por la violencia. Sus tierras han sido invadidas una y otra vez, y han tenido que luchar y defenderse en muchas ocasiones. Después de la rebelión de Juan Santos a mediados del siglo XVIII, no hubo ningún otro intento de ingresar a territorio Asháninka por cerca de cien años. Estos nuevos intentos se produjeron en la segunda mitad del siglo XIX, cuando el gobierno de Ramón Castilla comenzó a fomentar la conquista de esta región, ya que las haciendas de la costa peruana necesitaban mano de obra india para la producción de caña de azúcar y algodón luego de la liberación de los esclavos negros.

En 1891, el gobierno peruano pagó una deuda al gobierno británico con la concesión de una cantidad enorme de tierras en esta región de la selva. Estas tierras fueron a su vez concedidas a la Peruvian Corporation Limited, también conocida en la región como «La Colonia del Perené». Esta consistía en una gran plantación de café de más de 500 mil hectáreas de extensión. Por supuesto, varios asentamientos indígenas se encontraban en medio de las tierras concedidas a la Peruvian Corporation, que no tardó en proveerse de mano de obra. Hacia 1907, ya habían unos 14 mil «colonos» asentados en la región. Hacia 1938, unos dos mil Asháninka trabajaban en estas haciendas en condiciones de semi-esclavitud. Durante todos estos años, los Asháninka continuaron resistiendo. Las últimas rebeliones armadas contra los colonos blancos o mestizos ocurrieron en la década de los treintas.

A partir de los años cuarenta, el número de migrantes a la región se incrementó considerablemente. Los gobiernos de turno fomentaban abiertamente la colonización de estas tierras. En la década de los sesenta, una columna guerrillera llegó también a territorio Asháninka, seguida de cerca por el Ejército Peruano. Esta columna formaba parte del MIR (Movimiento de Izquierda Revolucionaria), uno de los diversos grupos guerrilleros que aparecieron en el Perú inspirados en la revolución cubana. Algunos Asháninka se incorporaron a la guerrilla, mientras otros huían de ella. Finalmente un grupo de jefes Asháninka entregaron a los líderes de la guerrilla al Ejército.
Todas estas experiencias han cimentado la fama guerrera del pueblo Asháninka. En el imaginario peruano es común representar a los Asháninka con arcos y flechas. En este sentido es importante insistir que los Asháninka son guerreros porque han tenido que aprender a defender sus vidas y sus tierras. Es más, esta lucha no ha terminado todavía. En las últimas décadas han tenido que enfrentar la presencia de Sendero Luminoso y del MRTA; y aún hoy en día siguen enfrentando a otros invasores.

La primera acción armada de Sendero Luminoso tuvo lugar en Chuschi, una pequeña aldea andina en las inmediaciones de Ayacucho, en Mayo de 1980. Durante los primeros años de la guerra, las acciones armadas y los actos terroristas se restringieron a las altas zonas sur-andinas y eventualmente a la capital, Lima. Sin embargo, a partir de 1982, y como consecuencia de la acción represiva de las Fuerzas Armadas peruanas en la región de Ayacucho, Sendero tuvo que desplazarse hacia otras zonas, entre ellas, a la cercana y muy estratégica región de la selva central, es decir, al corazón del territorio Asháninka. Unos años después, el MRTA también llegaría a la selva central huyendo de las Fuerzas Armadas, aunque en esta ocasión no venían desde el sur, sino desde los Andes centrales, al oeste del territorio Asháninka.

El clima de violencia en la región se incrementó durante la segunda mitad de la década de los ochenta. Al final de la década, Sendero Luminoso y el MRTA tenían bajo su control varias provincias de la región. Sendero controlaba la provincia de Satipo (ubicada hacia el sudeste), y el MRTA la provincia de Oxapampa (hacia el norte). Y ambos grupos se peleaban el control de la tercera provincia de la región. Chanchamayo, que se ubica entre Oxapampa y Satipo. Dada esta situación, en 1988, el Presidente García declaró la región en «estado de emergencia», es decir, bajo control militar.

En 1989, el MRTA asesinó a un importante líder Asháninka -un «pinkatzari» o «gran jefe»- de la provincia de Oxapampa. La respuesta del pueblo Asháninka no se hizo esperar. Inmediatamente organizaron un contigente armado, al que llamaron «Ejército Asháninka», y declararon la guerra al MRTA. En unas cuantas semanas el Ejército Asháninka tomó control de las principales ciudades y carreteras de la región, y en menos de dos meses cumplió su objetivo de expulsar al MRTA de Oxapampa sin mayor derramamiento de sangre. Este evento, por supuesto, fue cubierto por la prensa nacional e internacional, y muchos líderes Asháninka fueron entrevistados, pudiendo expresar su opinión a través de los diferentes medios.

En estos mismos años, en la provincia de Satipo, Sendero Luminoso controlaba la vida y el destino de miles de Asháninka. Después de casi una década de acciones políticas y militares en la región, Sendero había asumido el control de prácticamente toda la zona rural de la provincia. En esta región la principal vía de transporte y comunicación son los ríos Ene y Tambo. Hacia fines de los años ochenta, Sendero controlaba el tránsito de personas y de cosas a través del río Ene, y en la mitad del río Tambo. En esta zona crearon las llamadas «bases de apoyo» o «comités de apoyo». Estas «bases» eran, para los Asháninka, 
prácticamente campos de prisión. Si bien es cierto que varios Asháninka eran miembros activos de Sendero, e incluso algunos de ellos llegaron a ser jefes locales, la mayoría de los Asháninka sentían que esta era una guerra ajena. Es más, para la mayoría de los Asháninka, la vida en las «bases de apoyo» era una vida de esclavitud. No podían moverse con libertad en su propio territorio, su vida cotidiana se hallaba regida por horarios y tareas fijadas por Sendero, y tenían que trabajar obligatoriamente para sus jefes, la mayoría de los cuales eran foráneos. Debido a la situación de guerra, muchas veces la comida no alcanzaba para todos y era reservada para los jefes, mientras que el resto comían raíces e insectos para poder sobrevivir. En estos años, unos diez mil Asháninka, aproximadamente, vivían en estas condiciones. En 1991 tuve la oportunidad de visitar algunos de estos campos, entonces recientemente «liberados» de Sendero, y pude escuchar las terribles historias de aquellos que lograron sobrevivir. Esta actitud de Sendero para con el pueblo Asháninka se explica por razones ideológicas. De acuerdo a la ideología senderista, los Asháninka, al igual que otros pueblos indígenas, son «atrasados» y es necesario «civilizarlos»y «modernizarlos», su cultura y modos de vida deben ser destruidos y reemplazados por otros auténticamente revolucionarios, y si alguien se opone también tiene que ser eliminado.

A partir de 1991, varias comunidades Asháninka también se organizaron para enfrentar a Sendero y así poder recuperar su libertad y sus tierras. En este mismo año, las Fuerzas Armadas, bajo la dirección del entonces recientemente elegido Presidente Fujimori, también comenzaron a implementar una estrategia más ofensiva contra Sendero Luminoso en la región. En 1991, el Ejército Peruano instaló varios campamentos militares a lo largo de los ríos Ene y Tambo. Esto también explica, en parte, por qué, a diferencia de sus paisanos de Oxapampa, los Asháninka en esta zona crearon «rondas» o «comités de auto-defensa». Muchas de estas «rondas» habían sido creadas por la población de manera autónoma, y en algunos casos tenían ya varios años de existencia, dedicándose a la captura de abigeos y ladronzuelos, y a resolver conflictos al interior de la comunidad. Sin embargo, el gobierno de Fujimori decidió controlarlas, y en 1992 decretó una ley poniéndolas bajo la dirección de las Fuerzas Armadas. Esta situación generó un conjunto muy complejo de relaciones entre los Asháninka y las Fuerzas Armadas, que iban de la más estrecha colaboración, al abuso y la explotación. En algunos casos, las «rondas» Asháninka tenían mayor autonomía y libertad de acción, mientras que en otras zonas dependían más de las autoridades militares, que utilizaban a los Asháninka como guías, soldados de segunda clase, o simplemente como peones y sirvientes en sus campamentos. En todo caso, dadas las circunstancias, la mayoría de los Asháninka de la región preferían lidiar con los militares, a los que veían como invasores provisionales, antes que con Sendero Luminoso y la amenaza de destrucción total.

El Presidente Fujimori en persona asumió un rol activo en la acción de las Fuerzas Armadas. Desde 1991, comenzó a viajar a diferentes zonas rurales del país con la finalidad de entregar armas a los «comités de autodefensa» y a las «rondas» bajo el control del Ejército. Como era de esperarse, los medios se interesaron enormemente en todos estos asuntos. Un gran número de periodistas, con sus micrófonos, cámaras y grabadoras, seguían al Presidente en sus viajes y recorridos. La imagen del Presidente Fujimori entregando armas a las «rondas» se volvió muy popular, y si los que recibían estas armas eran «indios exóticos», tanto mejor. Así, los Asháninka comenzaron a aparecer con mayor frecuencia en las noticias, en las fotos de los diarios, y sobre todo en la televisión. Por supuesto, la prensa internacional también participaba en este peregrinaje para ver cómo el Presidente Fujimori repartía escopetas de caza a los ronderos Asháninka, vestidos con su tradicional «cushma», con los rostros pintados para la guerra, y llevando al hombro sus arcos y flechas.

El gobierno Peruano promovía, por supuesto, la difusión de estas imágenes. El Estado no sólo tenía que ganar la guerra contra Sendero Luminoso en medio de la selva tropical o en las altas montañas de los Andes, sino que también necesitaba mostrar a todos los ciudadanos peruanos cómo era que estaban ganando. Y qué mejor imagen que la de estos exóticos «otros», los «temibles guerreros Asháninka», que apoyaban al gobierno y al Ejército contra Sendero. De esta manera los «Asháninka» se convirtieron en ejemplo de ciudadanía. El resto de ciudadanos debían aprender de esta gente, que a pesar de ser «salvajes» eran también «héroes» de la patria.

El uso de estas imágenes también trajo consecuencias trágicas para el pueblo Asháninka. En 1993, un grupo de ronderos Asháninka participó, siguiendo órdenes del Ejército, en un desfile militar. Todos los 29 de Julio, un día después de la celebración de las fiestas patrias (conmemorando el aniversario de la independencia peruana), las Fuerzas Armadas organizan un desfile en una zona céntrica de Lima. Este desfile dura toda la mañana, y en él participan las distintas divisiones de las Fuerzas Armadas. Numerosos grupos de gente asisten, y por supuesto, todo el desfile es transmitido en directo y a nivel nacional por la televisión, para que lo puedan ver en todos los hogares peruanos. Como señalaba, en 1993, un grupo de ronderos Asháninka también participó en este desfile. Esto era algo especial, ya que es inusual que civiles tomen parte activa en el desfile. Sin embargo, los Asháninka no eran los únicos. Otros «ronderos» y también «ronderas» de distintas partes del país desfilaron ese día, codo a codo con los soldados. Los Asháninka resaltaban por el uso de sus vestimentas tradicionales y por sus arcos y flechas. Por supuesto, los locutores y narradores de la televisión se encargaban de resaltar la presencia de estos exóticos personajes, por si algunos más despistados no lo habían notado. En el desfile, cada grupo de ronderos era precedido por una banderola en la que se leía el lugar de donde provenían. Un par de semanas después, el 18 de Agosto, una columna armada de Sendero Luminoso atacó a varias de las comunidades que participaron en el desfile, llegando a masacrar a más de 60 personas, incluyendo mujeres, ancianos y niños. Por supuesto, los periodistas y cámaras de televisión también llegaron al lugar de los hechos para cubrir este evento. 


\section{Los Aguaruna: Defensores de la Patria}

Los Aguaruna viven en el norte del Perú, en la frontera con el Ecuador, al igual que otros pueblos indígenas. En esta región también viven los pueblos Huambisa, Shuar, Achuar y Shiwiar. Todos estos pueblos son Jívaros, es decir, pertenecen a la misma familia lingüística. Esto significa que sus idiomas tienen un origen común, son parecidos, y con cierto esfuerzo pueden entenderse unos y otros. Además del idioma, estos pueblos se han relacionado entre sí durante siglos, a través de guerras, intercambios comerciales y alianzas matrimoniales.

Los límites establecidos por los Estados actuales del Perú y Ecuador han complicado más estas relaciones. Todos los Aguaruna y Shiwiar viven dentro del territorio peruano; los Achuar viven a ambos lados de la frontera; y todos los Shuar viven en el Ecuador. Los Huambisa constituyen un caso particular porque, aunque viven en el Perú, sin embargo se hallan estrechamente vinculados a los Shuar a través de alianzas comerciales y matrimoniales. El mero hecho de vivir, pues, en una zona de frontera ha hecho las cosas difíciles para estos pueblos, sin embargo esta situación se agrava debido al largo conflicto entre ambos Estados. Este conflicto consiste en el reclamo, de parte de Ecuador, de un largo territorio amazónico que se extiende desde la actual frontera hasta la margen izquierda (norte) de los ríos Marañón y Amazonas.

Los orígenes de este conflicto se remonta por más de un siglo, hasta fines de la época colonial, y al nacimiento de los nuevos Estados nacionales después de las guerras de Independencia (Cayo, 1995). Durante la Colonia, ambos países formaban parte del Virreinato del Perú, pero no de la misma manera. La mayor parte de lo que ahora es Ecuador correspondía a la Audiencia de Quito, mientras el Perú actual corresponde al de varias Audiencias. Además, no podemos olvidar que Lima (y el Perú) eran la sede del Virreinato, lo cual también conllevaba celos y rivalidades. El Ecuador argumenta, pues, que el territorio amazónico que reclaman ahora formaba parte de la Audiencia de Quito.

$\mathrm{El}$ antecedente inmediato del presente estado de cosas se remonta a la guerra que hubo entre ambos países en 1941. En realidad, esta guerra tuvo como escenario la zona límitrofe de ambos países que se encuentra en la costa, a orillas del Océano Pacífico, y no en la Amazonía. Sin embargo, el conflicto actual es por territorio amazónico. El Perú ganó la guerra, y se firmó un acuerdo de paz, contando con otros cuatro países como garantes: los Estados Unidos, Brasil, Argentina y Chile. A partir de este tratado se fijaron los límites entre ambos países, y se nombró a una comisión para que coloque los hitos físicos. Sin embargo, $71 \mathrm{~km}$., ubicados en la Cordillera del Cóndor quedaron sin ser marcados, lo cual ha sido motivo de nuevos conflictos.

Inmediatamente después de la guerra, ambos países instalaron campamentos militares en las zonas fronterizas. En el lado peruano, excepto por los campamentos militares y un par de pueblos pequeños, la mayoría de la población de esta región es Aguaruna. Por supuesto, otros grupos de foráneos (españoles o peruanos) habían intentado asentarse antes en la zona. De hecho, el primer poblado español en esta región fue fundado en 1546, pero no duró por mucho tiempo antes de ser saqueado y destruido por los fieros pueblos Jívaro, los famosos reducidores de cabezas. Desde entonces, y debido a la difícil geografía de la región, el número de foráneos que llegaban como colonos o aventureros ha sido muy pequeño. Sólo en el presente siglo, a partir de los años cuarenta, y con el apoyo del Ejército, es que estos foráneos han podido establecerse finalmente,

En la década de los sesenta, el Estado Peruano fomentó diversos proyectos de colonización en la zona (Martínez, 1980). Algunos de éstos fueron organizados por el Ministerio de Guerra, y formaban parte de una política más general de poblar las zonas de frontera del país. A esta política se le conoce con el nombre de «fronteras vivas». La idea es crear asentamientos en zonas despobladas, o para ser más exactos, se trata de que ciudadanos peruanos vivan en estas zonas, y así evitar que ciudadanos de otros países se asienten dentro del territorio nacional. En el caso del Perú, esta política resulta algo irónica. La mayoría de tierras fronterizas se encuentran en la Amazonía, y ciertamente estas áreas no están despobladas. Eso sí, sus habitantes son indígenas, como los Aguaruna, Huambisa, o Achuar, que viven en la frontera con el Ecuador. El problema no es entonces de despoblamiento, sino de «identidad nacional» especialmente porque se trata de pueblos indígenas.

El problema de la identidad nacional de los indígenas tiene una larga historia en el Perú. Hacia fines del siglo XIX, después de la Guerra del Pacífico (entre Perú y Chile), este fue un asunto largamente discutido por políticos e intelectuales. Es muy conocida la anécdota de que durante la guerra habían «indios»" que creían que la guerra era entre un General llamado «Perú» y otro General llamado «Chile». Así nació lo que en el Perú se ha llamado «el problema del indio», es decir, qué es lo que va a hacer «el Perú» con «sus indios». Y hasta cierto punto, se podría afirmar que es un problema que nunca se ha resuelto de todo en el Perú ${ }^{6}$.

Volviendo a nuestro caso, podríamos decir que el Estado Peruano no se sentía seguro sabiendo que estas tierras estaban habitadas sólo por «indios» que no tenían idea de lo que era ser peruano o ecuatoriano. El Estado necesitaba ciudadanos peruanos «de verdad», patriotas que puedan defender estas tierras en caso de necesidad. Por ello, estos proyectos especiales de colonización incluían a solda-

5. Es necesario indicar que, en esta época, cuando se hablaba de «indios» se trataba de «indios andinos». Los «indios» de la Amazonía no existían ni en el imaginario ni en el discurso público. Uno de los primeros documentos oficiales en los que se hace la distinción entre «indios» de los Andes y de la Amazonía fue el Código Penal de 1924 (art.44-45), en el cual se habla de «indios semi-civilizados» para referirse a los de los Andes, y de «indios salvajes» para referirse a los amazónicos.

6. En los años noventa, por ejemplo, se siguen presentando a los indígenas amazónicos como salvajes. En una serie de programas docu mentales hechos para la televisión, y en los que se buscaba resaltar la variedad de paisajes y la riqueza ecológica del Perú, el reportero y coordinador de la serie comentó, refiriéndose a una comunidad de indígenas que viven dentro de los límites del Parque Nacional del Manu, como «casi humanos». 
dos retirados o «licenciados», así como campesinos de otras partes del país que ofrecieran garantías acerca de su «peruanidad».

La relación entre los militares, los «colonos», y los Aguaruna siempre ha sido muy difícil. Desde el establecimiento de los primeros campamentos militares, a inicios de los años cuarenta, los Aguaruna han sido sujeto de muchos abusos. No sólo han perdido muchas de sus tierras, apropiadas para fines militares o entregadas a «colonos», sino además las mujeres han sido violadas, y muchos Aguaruna, incluyendo niños han tenido que trabajar de manera forzada para los militares, muchas veces en condiciones casi de esclavitud.

En 1981, en el cuarenta aniversario de la guerra, se produjo un conflicto armado en la «Cordillera del Cóndor» entre el Perú y Ecuador. El conflicto no duró mucho, y poco tiempo después las cosas volvieron a la normalidad. Sin embargo, en los noventa, la tensión en la frontera volvió a incrementarse. En estos años, el Ejército Peruano se hallaba concentrado en su lucha contra Sendero Luminoso y contra el MRTA. Las fronteras no eran la primera prioridad. En 1995 otro conflicto armado estalló en la misma «Cordillera del Cóndor». La parte más fuerte del conflicto duró un par de meses, pero sus consecuencias se han prolongado hasta 1998, en que finalmente se ha firmado otro acuerdo de paz.

Durante los conflictos armados, los Aguaruna, al igual que los Asháninka, también fueron utilizados por los militares como guías y como soldados de segunda clase. Y al igual que los Asháninka, también se volvieron un elemento atractivo en las noticias diarias. La televisión mostraba a los «exóticos» líderes Aguaruna "coronados con plumas o usando pieles para cubrirse la cabeza”, pero llevando al mismo tiempo banderas peruanas. Muchos programas aprovecharon la ocasión para recordar a los televidentes que estos Aguaruna eran los mismos que reducían cabezas en el pasado. En algunos casos también se podía ver en plena acción a estos «fieros» sujetos, guiando a los soldados a través de enmarañadas junglas. Y por supuesto, también podíamos ver al Presidente Fujimori entregando armas, dando instrucciones o saludando a los patrióticos guías. Una vez más, exóticos indios se convertían en héroes y modelos de ciudadanía. Y el hecho de que se trataba de gente que podía tener dudosas nociones sobre lo que podría ser la nacionalidad peruana los convertía en mejores ejemplos aún ${ }^{7}$.

\section{Desde otra perspectiva...}

En la presentación que acabo de hacer de estos dos casos he enfatizado cómo los medios y el gobierno presentan y utilizan la imagen de estos peruanos «exóticos» de acuerdo a sus propios intereses, como son ganar la guerra contra Sendero Luminoso, el MRTA o el Ecuador, y al mismo tiempo legitimarse ante la ciudadanía peruana. De acuerdo a esta perspectiva, la gente Asháninka y Aguaruna, y sus líderes, aparecen como meros instrumentos pasivos en manos de otros. Sin embargo, ésto es sólo un lado de las cosas, que son más complejas. Es pues necesario ver cómo estos pueblos también han utilizado a los medios y al Estado de acuerdo a sus propios intereses.

Las guerras a las que nos hemos referido corresponden, en gran parte, a intereses totalmente ajenos a los de estos pueblos, aunque, como también hemos visto, se involucraron en ellas de forma más o menos voluntaria. Estas guerras amenazaban de forma directa la vida y las tierras indígenas, y si no intervenían en ellas, ponían en riesgo su sobrevivencia física y cultural como pueblos. Sin embargo, una vez que el peligro más inmediato pasó, sus líderes aprendieron a usar las mismas imágenes exóticas que habían sido creadas por otra gente, para obtener otros beneficios.

En primer lugar, usaron los medios para aparecer públicamente, en la televisión nacional e internacional, como Pueblos Indígenas. A través de estas imágenes mostraron algunos aspectos de su propia historia y cultura a la mayoría de ciudadanos peruanos. Mostraron cómo podían ser «diferentes»y al mismo tiempo ciudadanos peruanos, capaces incluso de actos heróicos. En otras palabras, presentaron a la comunidad nacional maneras distintas en las que se podía ser peruano.

De cara al Estado, usaron la legitimidad que el gobierno y la figura del Presidente Fujimori les dio para obtener ciertos beneficios para sus pueblos. Eran héroes de la patria, y como tales debían reclamar sus derechos. Así, comenzaron a presionar al gobierno a través de los medios, reclamando los títulos de sus tierras, escuelas, hospitales, y otros servicios.

A través de estas experiencias descubrieron cómo a los medios les gustaba mostrar lo «exótico». Así aprendieron también a «exotizarse», a atraer la atención de los medios exagerando ciertos rasgos «exóticos». Así, comenzaron a vestirse con sus trajes tradicionales, y a llevar sus plumas, arcos y flechas, cada vez que querían tener acceso a la prensa. Más de una vez, las cámaras de televisión han registrado las imágenes de líderes y delegados indígenas así vestidos, aproximándose al Palacio de Gobierno o a las distintas autoridades estatales. O si querían atraer la atención sobre algunos de sus más acuciantes problemas, también tenían que ofrecer a cambio algo más exótico. Así, por ejemplo, para que los periodistas hicieran algún reportaje especial sobre el problema de la propiedad de las tierras, también tenían que llevarlos donde un shamán o a que presencien algún rito tradicional. Por supuesto, una mayor presencia de los indígenas en la televisión no ha resuelto sus problemas. Lo que sí viene ocurriendo es que los indígenas van descubriendo y apropiándose de nuevas formas de lucha y nuevas estrategias para conseguir sus objetivos. Una de estas formas más recientes es el uso de la Internet, como veremos a continuación.

7. En el caso del Ecuador, también ocurrió algo similar, y el Estado y los medios también presentaron a los patrióticos Shuar. Cf. Gallardo et al, 1995; and, Ortiz et al. 1995 


\section{THE ASHANINKA AND THE INTERNET}

Desde que fue creado, el movimiento indígena en la Amazonía ha dependido de sus contactos internacionales. Incluso algunos estudiosos como Alison Brysk señalan cómo «el movimiento por los derechos indígenas nació como un movimiento trans-nacional» (1994: 32). La red internacional vinculada al movimiento indígena de la Amazonía incluye a una gama muy variada de instituciones y de gente: grupos de denuncia y acción solidaria como IWGIA (International Work Group of Indigenous Affairs) o Cultural Survival; comités y congresos de antropólogos, como los del Grupo de Barbados que nació en 1971; el recientemente creado grupo de trabajo especial sobre asuntos Indígenas de Naciones Unidas, al que habría que sumar los distintos informes y documentos elaborados por sus funcionarios a lo largo de décadas; y por supuesto, las propias organizaciones indígenas de carácter internacional, como la Coordinadora Indígena de la Cuenca Amazónica, COICA. Esta acción a nivel internacional adquiere mayor importancia en el caso de los indígenas amazónicos, que son minorías absolutas en sus propios países. En el Perú, por ejemplo, constituyen tan sólo el $1.5 \%$ del total de la población nacional. La alianza con estas organizaciones internacionales les permite ejercer cierta presión sobre los distintos gobiernos, cosa que no podrían hacer muchas veces por sí solos. Por ello, desde un inicio, el escenario internacional ha sido un lugar clave para la lucha de estos pueblos.

En este sentido podemos apreciar cómo, en la última década, los avances tecnológicos han permitido ampliar la acción del movimiento indígena. Hoy en día es común que los líderes indígenas viajen por todo el mundo para participar en congresos y conferencias, promover sus causas y buscar apoyo económico. Por eso no resulta extraño que algunos, como Marc Edelman, han comenzado incluso a hablar de la creación de una especie de «jet set» de líderes Indígenas (Edelman, 1996). Estas nuevas prácticas han generado, pues, nuevas maneras de entender y vivir el liderazgo y la política indígenas, al mismo tiempo que se generan nuevos problemas y tensiones, sobre todo en la relación entre líderes y sus pueblos. Sin embargo, en esta ocasión no voy a entrar a detallar la complejidad de estas prácticas y las nuevas relaciones sociales que van generando.

Otra nueva práctica es el uso de la «Internet». Cada vez hay más y más organizaciones indígenas y grupos de solidaridad que empiezan a actuar a través de esta «red global». Es más, como su propio nombre lo indica, el uso de Internet ha posibilitado la creación de «redes» en las cuales estos distintos grupos y otras personas interesadas se ponen en contacto y actúan en común. Uno de estas redes es la llamada «Red Nativa» o «Native Web», a través de la cual uno puede acceder o vincularse (si traducimos literalmente el término «link») con muchas estas organizaciones. En Internet también se pueden encontrar noticias y boletines informativos sobre sucesos de actualidad de los distintos pueblos indígenas, como el de «Abya Yala» (http://saiic.nativeweb.org/ayn).

Pero en este artículo quiero concentrarme en la forma en que los pueblos indígenas de la Amazonía peruana usan los medios, y por eso voy a fijarme en el caso de los Asháninka. Si uno ingresa a la Internete, puede encontrar dos «páginas web» o «lugares» («web sites») explícitamente relacionados con los Asháninka. Uno de ellos es un boletín, llamado Aviro, elaborado por una ONG peruana llamada PROCAM (http://www.eurosur.org/PROCAM/ aviropor). En este caso, si bien es cierto que la finalidad de este boletín es servir los intereses del pueblo Asháninka, sin embargo, la «página web» ha sido creada y es producida por la ONG. Correspondería, pues, al tipo de acción tradicional de los grupos de solidaridad con los indígenas, y en este sentido, no me interesa discutirlo ahora. En cambio, existe otra «página web» que ha sido creada y que es actualizada por una comunidad Asháninka en particular, la comunidad de Marankiari Bajo.

Este «web site» (http://ekeko.rcp.net.pe/ashaninka) contiene varias páginas. En la primera hay un indíce, que además, nos muestra una vista panorámica del bosque tropical y es además acompañada por las figuras de una corona tradicional (como la que usan los jefes Asháninka) rodeada de flechas. A través de esta página principal se puede acceder a otras seis páginas, todas con textos y fotografías. En una de ellas podemos informarnos de la geografía y clima del territorio Asháninka. Otra nos cuenta, de manera muy sintética, la historia de las invasiones y las luchas de resistencia de los Asháninka. En otra podemos leer una breve descripción sobre su idioma, y acceder a varios cuentos y leyendas, que se presentan en dos versiones, en la original Asháninka y con su traducción al castellano. Hasta la fecha, no se pueden leer todas estas narraciones. Un dato de interés es que estos cuentos, si bien hacen referencia a temas y mitos tradicionales, no son presentados como tales, sino como cuentos firmados por un autor (que además es quien hace las traducciones al castellano). En todas esta secciones, se habla del pueblo Asháninka en general.

Otro grupo de páginas están dedicadas, de manera más particular a la comunidad de Marankiari Bajo. En ellas nos explican dónde está ubicada la comunidad, cuántos habitantes tiene, sus principales actividades económicas, el dialecto Asháninka que hablan en la comunidad, y una breve síntesis de la historia de la comunidad. Finalmente, en otras páginas encontramos información sobre sus instituciones y organización política, así como los distintos tratados firmados con otras organizaciones indígenas a nivel regional, nacional e internacional.

Los Asháninka de Marankiari Bajo, al igual que los otros pueblos que hemos visto en secciones anteriores, también usan este novedoso medio de comunicación con una finalidad política. $\mathrm{Al}$ igual que el uso de la radio por el pueblo Shipibo, insisten en elementos que pueden reforzar su identidad étnica como "pueblo Asháninka». Las referencias a una tierra, historia y lenguaje común apuntan en esta dirección. Al mismo tiempo, insisten en la necesidad de articular su acción política en diversos niveles y con otras instituciones, sobre todo con otras organizaciones indígenas. Finalmente, a través de la Internet pueden «aparecer» ante los ojos de mucha gente en el mundo, mostrando quiénes son, y cuáles son sus problemas y sus intereses. 


\section{Una invitación para seguir adelante}

En los casos antes discutidos, he querido mostrar como diferentes pueblos indígenas, y en diferentes momentos, han usado los medios de comunicación para su acción política. Sin embargo, es preciso hacer algunas observaciones finales que pueden servir como punto de partida para seguir adelante, no sólo investigando, sino también actuando políticamente.

En primer lugar, es necesario mencionar que si bien es cierto que la Constitución peruana declara al Perú como país «multicultural», la marginación, explotación y racismo siguen existiendo y siguen destruyendo las vidas y culturas de muchos indígenas. La mayoría de peruanos sigue considerándose de «raza mestiza», sentimiento compartido también por políticos e intelectuales, tanto de derecha como de izquierda. En este contexto, los Pueblos Indígenas de la Amazonía siguen luchando por sus derechos, y buscando nuevas estrategias para sobrevivir y vivir mejor. Entre estas estrategias podemos incluir el uso cada vez más frecuente de los medios

Los pueblos Indígenas siempre han ocupado un lugar marginal en la historia del Perú. Por lo tanto, es muy necesario analizar, en toda su complejidad, las relaciones que se han establecido a lo largo de los siglos entre los distintos actores sociales, grupos, clases y pueblos en el Perú. A pesar de que los medios de comunicación anuncian cada cierto tiempo el «descubrimiento de alguna tribu nunca antes contactada por blancos», cosa muy dudosa por cierto, o precisamente por ello, es necesario fijar nuestra atención en esta historia de relaciones. Como hemos podido ver a lo largo de este artículo, las relaciones entre los pueblos indígenas, los medios y el Estado no son simples y unívocas. Hemos querido expresar la complejidad de estas relaciones, que también se expanden al ámbito internacional.

Finalmente, si hablamos de visibilidad y de comunicación, deberíamos ver y oír más a los propios indígenas expresándose con sus propias palabras y su propia acción política.

\section{REFERENCIAS Y BIBLIOGRAFÍA UTILIZADA}

BAllón, Francisco (ed.). 1982. Colonización en la Amazonía. Lima: CIPA.

Brown, Michael F. 1993. «Facing the State, Facing the World: Amazonía's Native Leaders and the New Politics of Identity», en L'Homme. 33 (2-4): 307-326.

Brown, Michael F. y Eduardo Fernández. 1991. War of Shadows: The struggle for Utopia in the Peruvian Amazon. Berkeley: University of California Press.

BRowne, Donald R. 1996. Electronic Media and Indigenous Peoples: A Voice of Our Own? Ames, Iowa: Iowa State University Press.

BRYSK, AlISON. 1994. «Acting Globally: Indian Rights and International Politics in Latin America», en VAN COTT, Donna Lee (ed). Indigenous Peoples and Democracy in Latin America. New York: St. Martin's Press-Inter American Dialogue. 1994. pp. 29-51.
Chaumeil, Pierre. 1990. «Les Nouveaux Chefs...» Pratiques politiques et organisations indigènes en Amazonie péruvienne», en Problèmes de Amérique Latine, 96: 95-113.

Chirif, Alberto. 1974. «Los Congresos de las Comunidades Nativas: El Inicio de la Participación», en Participación, 3 (5): 46-53.

EDELMAN, Marc. 1996. «Reconceptualizing and Reconstituting Peasant Struggles: A New Social Movement in Central America», en Radical History Review, 65: $26-47$

ESPINOSA, OsCAR. 1993. «Los Asháninka: Guerreros en una Historia de Violencia», en América Indígena, 53 (4): 45-60.

EsPINOSA, Oscar. 1994. La repetición de la violencia Informe sobre la situación de los Asháninka de los rios Ene y Tambo. Lima: Centro Amazónico de Antropología y Aplicación Práctica.

EsPinOSA, OsCar. 1995. Rondas Campesinas y Nativas en la Amazonía Peruana. Lima: Centro Amazónico de Antropología y Aplicación Práctica.

EsPINOSA, OSCAR. 1996. «El pueblo Asháninka y su lucha por la ciudadanía en un país pluricultural», en Derechos Humanos y Pueblos Indígenas de la Amazonía Peruana. Lima: Asociación Peruana de Estudios para la Paz-APEP \& Centro Amazónico de Antropología y Aplicación Práctica. pp. 77-132.

Gallardo, José et al. 1995. Tiwintsa. Quito: Editorial El Conejo.

GinsBurg, FAYe. 1997. «*From Little Things, Big Things Grow+ Indigenous Media and Cultural Activism,» en FOX, RICHARD \& ORIN STARN. Between Resistance and Revolution: Cultural Politics and Social Protest. New Brunswick, NJ: Rutgers University Press.

Hale, Charles R. «Cultural Politics of Identity in Latin America» en Annual Review of Anthropology, 26: 567. 590.

MarTínez, HéCtOR. 1980. Migraciones Internas en el Perú. Aproximación crítica y bibliográfica. Lima: Instituto de Estudios Peruanos.

Meyrowitz, Joshua. 1985. No Sense of Place. The Impact of Electronic Media on Social Behavior. New York \& Oxford: Oxford University Press.

Morín, FranÇOISE. 1992. «Les Premiers Congrès ShipiboConibo dans le contexte politique et religieux des Années 60-70», en Journal de la Société des Américanistes, 78 (2): 59-77.

Ortiz, Benjamín, et al. 1995. Tiwintza: La Dignidad de un Pueblo. Quito: Fundación José Peralta \& Centro de Educación Popular-CEDEP.

Pease GarCía, Henry. 1977. El ocaso del poder oligárquico. Lucha política en la escena oficial, 1968-1975. Lima: Centro de Estudios y Promoción del Desarrollo (Desco). 3a ed. 1980

Riggins, Stephen H. 1992. Ethnic Minority Media. An International Perspective. London \& New Delhi: Sage Publications. 
Seymour-Smith, Charlotte. 1988. Shiwiar. Identidad étnica y cambio en el río Corrientes. Quito: FLACSOIFEA.

SMITH, RichaRd CHASE. 1985. «A Search for Unity Within Diversity. Peasant Unions, Ethnic Federations, and Indianist Movements in the Andean Republics», en Macdonald, Theodore, Jr. (ed). Native Peoples and Economic Development. Six Case Studies from Latin America. Cambridge, MA: Cultural Survival. pp. 5-38.

Van Cott, Donna Lee (ed). 1994. Indigenous Peoples and Democracy in Latin America. New York: St. Martin's Press - The Inter-American Dialogue.

Veron, Eliseo y Silvia Sigal. 1986. Perón o Muerte. Los fundamentos discursivos del fenómeno peronista. Bs.Aires: Legasa.
WRight, RoBin. 1988. «Anthropological Presuppositions of Indigenous Advocacy,» en Annual Review of Anthropology, 17: 365-426.

\section{INTERNET:}

Abya Yala (http://saiic.nativeweb.org/ayn)

Aviro (http://www.eurosur.org/PROCAM/aviropor) Marankiari Bajo (http://ekeko.rcp.net.pe/ashaninka)

\section{RESUMEN}

Los pueblos indígenas de la Amazonia Peruana y el uso político de los medios de comunicación.

Este artículo trata sobre el uso político de los medios de comunicación (radio, televisión e Internet) por parte de los pueblos indígenas de la Amazonia Peruana. En particular, analiza la utilización que el pueblo shipibo ha hecho de la radio en el proceso de construcción de su identidad étnica y en la creación de sus organizaciones políticas representativas; el tipo de vinculación de los pueblos Ashaninka y Aguaruna, el estado y la televisión sobre todo en la redefinición del concepto de identidad nacional en el contexto de diferentes conflictos armados, y finalmente, se presenta el uso de Internet por el pueblo Ashaninka.

El objetivo principal del articulo es mostrar como el empleo de los medios de comunicación permite a las comunidades indígenas hacerse más visibles y actuar políticamente en distintos espacios públicos.

Palabras claves: Perú, Shipibo, Ashaninka, Aguaruna, identidad nacional, medios de comunicación de masas.

\section{ABSTRACT}

The indigenous peoples of the Peruvian Amazonas and the policital use of the mass media

This article deals with the political use of the means of communication (radio, tv, Internet) by the indigenous peoples of the Peruvian Amazonas. In particular, it analyzes the use made by the Shipibo people of the radio in the construction of their ethnic identity and the creation of representative political organization; the links among the Ashaninka and Aguaruna peoples, the state and the tv in the redefinition of the national identity in the context of armed conflicts, and finally, it presents the use of Internet by Ashaninka people.

This article aims at showing that the use of mass media allows indigenous groups to become more visible and to act in different political scenarios.

Key words: Peru, Shipibo, Ashaninka, Aguaruna, national identity, mass media. 